\title{
Experiences of Community-Dwelling Older People With Dementia Participating In A Person-Centered Multidimensional Interdisciplinary Rehabilitation Program
}

\author{
Anna Sondell ( $\square$ anna.sondell@umu.se ) \\ Umeå University https://orcid.org/0000-0002-0654-4661 \\ Josefine Lampinen \\ Umeå University \\ Mia Conradsson \\ Umeå University \\ Håkan Littbrand \\ Umeå University \\ Undis Englund \\ Umeå University \\ Ingeborg Nilsson \\ Umeå University \\ Nina Lindelöf \\ Umeå University
}

Research article

Keywords: Dementia, Rehabilitation, Interdisciplinary, Experiences, Qualitative research, Aged

Posted Date: October 22nd, 2020

DOI: https://doi.org/10.21203/rs.3.rs-94537/v1

License: (c) (1) This work is licensed under a Creative Commons Attribution 4.0 International License.

Read Full License 


\section{Abstract}

Background: There is a great need for the development of feasible rehabilitation interventions for older people with dementia. An increased understanding of this population's experiences of rehabilitation program participation is therefore important. The purpose of this study was to explore how communitydwelling older people with dementia experienced their participation in a person-centered multidimensional interdisciplinary rehabilitation program.

Methods: Sixteen older people with dementia were interviewed about their experiences of participation in a person-centred multidimensional interdisciplinary rehabilitation program. The program comprised assessments by a comprehensive team followed by a rehabilitation period of 16 weeks among people with dementia and their informal primary caregivers. The interviews were conducted in close conjunction with the rehabilitation visits and analysed with qualitative content analysis.

Results: The analysis resulted in one overarching theme: Empowered through participation and togetherness and four sub-themes: Being strengthened through challenges; Gaining insights, motives, and raising concerns about the future, Being seen makes participation worthwhile, and Feelings of togetherness in prosperity and adversity. The participants increased their self-esteem by daring and coping in the rehabilitation. The insights about themselves and their condition motivated them to continue with their prioritized activities, but also raised concerns about how the future would play out. Collaboration in the group and being seen and acknowledged by staff strengthened their own motivation and self-efficacy.

Conclusion: A person-centered multidimensional interdisciplinary rehabilitation program seems feasible among community-dwelling older people with dementia according to reported experiences. The participants seemed empowered through the rehabilitation and reported mostly positive experiences and perceived improvements, which seemed to affect their wellbeing and daily life. Providers of interdisciplinary rehabilitation programs for this group should consider aspects raised by the participants e.g. the positive experience of being challenged in both exercise and daily activities; the importance of being seen and feeling secure; the benefits and challenges of collaboration with others in the same situation; and the generation of new perspectives of current and future situation. Trial registration: ISRCTN, ISRCTN59155421.http://www.isrctn.com/ISRCTN59155421. Registered November 32015.

\section{Background}

Dementia significantly influences all aspects of life for affected individuals, as well as for family members and friends in their immediate networks [1]. Dementia is the leading cause of dependence in activities of daily living (ADL) among older people [1]. In addition to gradually reduced cognitive function, deterioration of walking and balance abilities is common [2]. The reduced cognitive and functional abilities increase the risks of falls and fractures $[3,4]$, and the accompanying lack of initiative and interest $[5,6]$ increases the risk of low levels of social interaction [7] and daily physical activity [8]. Together, these 
factors can have negative effects on overall health $[9,10]$. Other dementia-related consequences that complicate care and have negative effects on health and quality of life include malnutrition, reduced oral health, drug-related problems [11], depression [12], and behavioral and psychological symptoms of dementia (BPSD) $[1,13]$. The presence of BPSD causes a great deal of stress for people with dementia, as well as for informal primary caregivers [14], and is the most common reason why people with dementia move to nursing homes [15]. Given this complexity, the achievement of success in interventions may be challenging, especially considering that people with dementia may also have limited awareness of their difficulties in everyday life and anxiety about participation in new situations and contexts [16]. Despite the difficulties posed by this condition, a great need exists for rehabilitation efforts during the course of dementia.

Rehabilitation is a set of interventions designed to optimize functioning and reduce disability among individuals with health conditions in interaction with their environment [17]. As rehabilitation seeks to optimize function, activity, and participation, and not to provide a cure, it should be offered to people with dementia despite the neurodegenerative nature of the disease [18]. In contrast to availability for people with other neurodegenerative diseases, e.g. multiple sclerosis [19] and stroke [20], rehabilitation programs are not routinely available for people with dementia in clinical settings [21-23]. Reasons for this situation, in addition to limited resources, may include the challenges involved in managing the complex consequences of dementia, as well as rehabilitation staff's attitudes regarding the ability of people with dementia to participate in rehabilitation $[22,24]$. In addition, people with dementia seem to have less access to rehabilitation in clinical settings after events such as hip fracture or stroke in comparison with people without cognitive impairment $[25,26]$. This discrepancy exists despite the findings of several studies demonstrating that the effects of rehabilitation after hip fracture in people with dementia are similar to or greater than those observed in people without cognitive impairment [27-29].

Although studies have evaluated different aspects of rehabilitation for people with dementia, few studies have evaluated rehabilitation provided by interdisciplinary teams comprised of many different professionals [30] in an outpatient setting [31-33]. This form of rehabilitation might be a successful approach to managing the complexity of dementia. Thus, interdisciplinary rehabilitation for people with dementia, needs to be further explored. To increase knowledge about feasibility and broaden acceptance of the relevance of interdisciplinary rehabilitation programs for people with dementia, it is important to not only investigate the programs' impacts, but also to explore the experiences of program participation. These knowledge can be important to evaluate the feasibility of rehabilitation programs and when planning and conducting rehabilitation for older community-dwelling people with dementia. The aim of the present study was to explore the experiences of community-dwelling older people with dementia who took part in a person-centered multidimensional interdisciplinary rehabilitation program.

\section{Methods}

\section{Study context}


This qualitative study was undertaken in the context of the Multidimensional Interdisciplinary Rehabilitation in Dementia (MIDRED) study conducted in Umeå, Sweden in 2016. The study is a randomized controlled study evaluating a person-centered multidimensional interdisciplinary rehabilitation program for community-dwelling older people with dementia, including education and counseling of informal primary caregivers. The study protocol is published online at http://www.isrctn.com/ISRCTN59155421. Participants to the MIDRED study were recruited through local health centers and the outpatient unit of the Geriatric Center, University Hospital of Umeå. The MIDRED study inclusion criteria were: diagnosis of dementia according to the 10th revision of the International Statistical Classification of Diseases and Related Health Problems in medical records, age $\geq 60$ years, Mini-Mental State Examination (MMSE) score $\geq 10$ [34], ability to stand up from a chair with armrests with help from no more than one person, ability to hear and understand Swedish sufficiently to participate in the assessments, expected survival time $>6$ months, approval from physician to participate in the study, and no initiation of a move to a nursing home. The participants $(n=61)$ were randomized to usual care or to a person-centered multidimensional interdisciplinary rehabilitation program for 16 weeks, including two follow-ups.

\section{Participants}

Sixteen of the 31 participants in the intervention group were invited to participate in the present interviewbased study. To achieve variation with regard to age, sex, family relationship, physical and cognitive function, depressive symptoms, attitudes toward program activities (negative, neutral, positive), and degree of adherence estimated by the rehabilitation staff (low, medium, high), the participants were purposefully selected. All 16 participants approached agreed to participate (Table 1). Baseline assessments were made by physiotherapists. The diagnoses were verified by a physician specialized in geriatric medicine according to the Diagnostic and Statistical Manual of Mental Disorders, 4th edition, text revision [35]. 
Table 1

Characteristics of the participants interviewed $(n=16)$

\section{Age, years}

Women

Alzheimer's disease

Mini-Mental State Examination [34], MMSE, (0-30)

Berg Balance Scale [36], BBS, (0-56)

Functional Independence Measure [37], FIM, (13-91)

Geriatric Depression Scale 15 [35], GDS-15, (0-15)

Living alone

Number of years in school

Adherence, high

Attitude, positive

Numbers are presented as median (range) or $\mathrm{n}(\%)$.

For MMSE (cognitive function), BBS (functional balance) and FIM (ADL), a higher score indicates better status. For GDS-15 (depression) a lower score indicates better status.

\section{Data collection}

Three of the authors (NL, IN, and AS) conducted one-to-one semi-structured interviews with open-ended questions in participants' homes or in a room at the clinic during the last two weeks of the intervention. To facilitate recall during interviews, the participants were shown pictures of the team staff and the interviewers had brief descriptions of the activities in which participants had taken part in and the team staff whom they had met during the intervention. The main questions, according to an interview guide, were: "What is your experience of taking part in the rehabilitation program?" and "In what way have the activities you participated in affected your everyday life today?". The participants were encouraged to speak freely in responding to the questions, and the interviews proceeded as conversations. Follow-up questions were asked when necessary. The interviews were audio-recorded, lasted 15-43 minutes (median 28.5 minutes), and were transcribed verbatim by a person not involved in the study.

\section{Data analysis}

In this qualitative study, data from individual interviews were analyzed using qualitative content analysis with an inductive approach according to Graneheim and Lundman [38, 39]. This method involves the stepwise, systematic analysis of communication, and a process of interpretation that focuses on similarities and differences that emerge from the material, and resulting in the organization of data into categories and themes [38, 39]. The Consolidated Criteria for Reporting Qualitative Research (COREQ) checklist was taken into consideration to ensure transparency [40]. The unit of analysis was all 
interviews. Two authors (AS, JL) read all the interview transcripts several times to obtain a sense of the whole. They also listened to the audio recordings to obtain further information from interviewees' tones, voices, and pauses. Next, the transcript content was divided into meaning units consisting of constellations of words and statements with the same meanings. Authors then condensed and coded the meaning units. Based on similarities and differences between codes, preliminary categories were clustered, abstracted, and merged, into ten categories. The interpretive process was mainly conducted by the first and second authors in several steps, and yielded four sub-themes and one theme. At meetings attended by all authors creation of categories, sub-themes and theme, were discussed and changes were made until consensus was achieved. The analytical process involved a back-and-forth movement between the whole and parts of the texts.

Trustworthiness was ensured, for example, by all co-authors participation in several steps of the analysis, and that each author had different pre-understanding, and both insider and outsider perspectives were represented. The disciplines and research areas represented were physiotherapy (AS, NL, HL, and MC), occupational therapy (JL and IN), and physician specialized in geriatric medicine (UE). All authors had experience working with older people with physical and cognitive impairments, and many (HL, NL, AS, JL, and UE) had experience with person-centered multidimensional interdisciplinary rehabilitation. The authors were involved in the planning of the MIDRED study (HL, MC, NL, IN, and JL), implementation of the intervention (JL and MC, and $\mathrm{HL}$ and NL as backup), and performance of the interviews (AS, NL, and IN). Two authors (NL and IN) had extensive experience in interviewing, and in the design and theoretical underpinnings of qualitative content analysis.

\section{Intervention}

The intervention program comprised assessments by a comprehensive team followed by a rehabilitation period of 16 weeks. The team staff included assistant nurse, dental hygienist, dietician, neuropsychologist, nurse, occupational therapist (OT), pharmacist, physician (MD), physiotherapist (PT), and social worker. This team identified problems, needs, and strengths among people with dementia: functional capacity, cognitive function, ADL performance, falls, participation in society, physical activity, nutrition, medical conditions, BPSD, and drug use. Based on the findings intervention needs were determined. Representatives of the team staff, together with each participant with dementia and his/her informal caregiver(s), formulated individual rehabilitation goals and planned continuous follow-ups. Based on goals, relevant professionals formed a rehabilitation team for each participant and planned specific interventions. At weekly meetings the professionals evaluated how the interventions were progressing, goal completion, and whether new problems had arisen for the participants. The interventions were conducted at the outpatient facilities at the Geriatric Center (referred to as day rehabilitation unit), in the homes of participants with dementia, and/or in community. Examples of individual-based interventions were prescription of cognitive technical devices, introducing participants with dementia to a day-care center and other activities in the community, support to informal primary caregivers, correction of participants' medication regimes, and support to prevent malnutrition. The informal primary caregivers were offered six group sessions and individual support when needed. 
Each participant also offered individualized physical exercise at the day rehabilitation unit twice a week. The participants travelled to the unit and participated in group exercise sessions followed by a coffee break. An assistant nurse was responsible for organizing transportation to the clinic. The assistant nurse and the other staff assisted the participants when arriving and leaving the clinic, and organized the coffee breaks making sure that the participants felt confident and welcomed. The individualized exercise was based on the High-Intensity Functional Exercise (HIFE) Program [41, 42] with the goal of improving muscle strength, balance, and gait ability. The individualized exercise was conducted in groups of three or four participants led by two physiotherapists. Participants also received individual recommendations and guidance for the achievement of recommended physical activity levels $[43,44]$.

\section{Results}

The analysis of the interviews revealed ten categories, four sub-themes and one theme. The latent message is interpreted in the theme: Empowered through participation and togetherness. The sub-themes are as follows: Being strengthened through challenges, Gaining insights, motives, and raising concerns about the future, Being seen makes participation worthwhile, and Feelings of togetherness in prosperity and adversity (Table 2). The quotations presented below and related to categories are attributed to participants with fictitious names in parentheses within the text below. Ellipses within the quotes indicate pauses. 
Table 2

Categories, sub-themes and theme

\begin{tabular}{|lll|}
\hline Category & Sub-theme & Theme \\
\hline Being challenged is rewarding & $\begin{array}{l}\text { Being strengthened through } \\
\text { challenges }\end{array}$ & $\begin{array}{l}\text { Empowered through } \\
\text { participation and } \\
\text { togetherness }\end{array}$ \\
$\begin{array}{ll}\text { Daring and coping provide } \\
\text { satisfaction and self-esteem }\end{array}$ & $\begin{array}{l}\text { Gaining insights, motives, and } \\
\text { reneration of new insights and } \\
\text { reflections }\end{array}$ & \\
$\begin{array}{l}\text { Striving to maintain } \\
\text { improvements and hoping for } \\
\text { continuation }\end{array}$ & \\
$\begin{array}{l}\text { Fearing the future } \\
\begin{array}{l}\text { Participation is viewed as a } \\
\text { privilege }\end{array}\end{array}$ & $\begin{array}{l}\text { Being seen makes participation } \\
\text { worthwhile }\end{array}$ & \\
\hline $\begin{array}{l}\text { Responsiveness and support } \\
\text { create security }\end{array}$ & & \\
\hline $\begin{array}{l}\text { Perceiving unfulfilled needs and } \\
\text { expectations }\end{array}$ & & \\
\hline Experiencing joy and friendship & $\begin{array}{l}\text { Feelings of togetherness in } \\
\text { prosperity and adversity }\end{array}$ & \\
\hline $\begin{array}{l}\text { Perceiving obstacles to } \\
\text { interaction }\end{array}$ &
\end{tabular}

\section{Empowered through participation and togetherness}

The overall theme describes that the participants gained empowerment to better handle their situation and everyday life, which was mediated by their experiences of the rehabilitation program. The participants went through a process, prompted by the challenges and expectations during the rehabilitation program, in which they progressed from feeling doubt and hesitation to feeling strengthened and competent. They got insights about the condition and themselves. Collaboration in the group, and being seen and acknowledged by staff, strengthened their own motivation and self-efficacy.

Being strengthened through challenges

\section{Being challenged is rewarding}

Participants initially felt unsure or hesitant about participating in the rehabilitation program, but they gradually changed their minds. They expressed that being challenged was rewarding, when this in turn led to successful management of achievable activities. "I told her [the occupational therapist] that we walked together, me and my husband...She thought I should try to walk by myself...So we decided I should 
try, and then I have been trying and it worked.. now I have walked so much ... all the time when I go out...t's like a sense of freedom." (Sally)

There were descriptions of everyday activities that the participants, because of the rehabilitation, felt more capable of doing, or that they could manage again; for example, being able to walk upstairs or rise from a chair without difficulty. They also discovered physical improvements during the exercise sessions as the program progressed. One woman stated that she prevented a fall when vacuuming due to increased balance and leg strength. Participants expressed increased awareness of how much they could push themselves during exercise and in everyday life: "I can go by myself... have my hairdresser here and the supermarket...it is not so far away and I manage it" (Sally).

It was described important that all rehabilitation activities offered were at an appropriate level and adjusted to each individual. They described the physical exercises as individualized and gradually increasing in difficulty to challenge them to improve further. The challenging exercises gave them a positive feeling after exercising: "...It is something very positive when you increase your strength all the time" (Andrew). Participants were surprised that the exercises made them sweat and have sore muscles. They realized that they would not have been able to exercise at the same challenging level by themselves since the exercises were sometimes very demanding and felt slightly dangerous.

\section{Daring and coping provide satisfaction and self-esteem}

Participants perceived themselves as being more competent in daily activities than before the rehabilitation period, which led to feelings of increased self-esteem. One participant mentioned that she had been praised for her progress, and another said that "I felt I was blossoming again." They expressed that they were happier and more satisfied when they dared to do more things, as they did in rehabilitation and in daily life. One woman said: "When I think about how I would have been if I had not been in the project, I think that I am much more alert and happier and dare to do more things than I would have otherwise " (Bridget). It was mentioned that they could handle their life situations better and felt joy when others thought they were more capable: "You maybe become a bit freer... when others think that you are capable..." (Elsa). Another positive aspect that participants mentioned was the opportunity to change their scenery when they traveled to the day rehabilitation unit. They described it as invigorating and reported that going outside their homes by themselves strengthened their self-esteem. "For me, it is about getting out of the house...because I have been so tied to the house...because I have an illness...and then you become stuck at home... Yes...really..." (Nea).

Leaving their partners at home when traveling to the day rehabilitation unit was a positive aspect, as it gave them opportunities to miss their partners: "I think it is good... it may be good to be apart for a while... I'm there for half a day, so she can find something else to do, then maybe I miss her...ha ha...just a thing like that..." (Eric). It was also expressed that the digital memory aids they received facilitated their everyday lives, for example by reminding them to take their medication or clarifying whether it was day or night: "It's perfect...Even if you think you know which day it is, it's easy to peek and check" (Boris). 


\section{Gaining insights, motives, and raising concerns about the future}

\section{Generation of new insights and reflections}

The rehabilitation program resulted in new insights and reflections. Participants expressed, for example, that they had the ability and desire to improve their situation, despite their condition: "You feel that you are good and see that you are at least as good...the ability to want to become a little better... am sure it is the same for you..." (Eric). Further, they realized that engaging in regular activities had a positive impact on their mood: "...to feel satisfied when I get home and feel how nice it was that I did this today" (Karen). It was emphasized that maintaining an exercise routine was easier when they experienced improvements during the rehabilitation process, and that this experience created motivation to continue. Being active and having something to participate in twice a week gave a sense of satisfaction, and was something for them to look forward to. They realized further that they were not alone in having dementia, and that dementia had many manifestations and affected people in different ways. When comparing themselves to others in the group, they reflected on the fact that some were in worse condition than others, which gave them insights that things could be even worse. "The most important thing, looking back, is that you realize that you are not alone in having problems..." (Adam).

\section{Striving to maintain improvements and hoping for continuation}

The participants described that they were striving to maintain the improvements that they had achieved during the rehabilitation. It was important for them to take responsibility and to plan to continue exercising after the rehabilitation period, on their own or in another form. Being persistent was described as a positive attribute. One man said, "I don't think I have any problem with, so to say, forcing myself to do regular exercise when I notice results so... it's important that you hang in there." (Boris).

Some participants had already made plans for continued engagement in activities, and others stated that they were going to continue with previously appreciated activities, such as visiting the library. They were also expected to continue exercising in other regimes, but some felt uncertain about how to carry out activities in the future. Despite help from the staff, others felt unsure about activities in general and about which activities to do, as well as doubts about daring to go to activities in the community by themselves. One woman hoped to include her husband in her training regime for support and togetherness: "I will try to get my spouse to join me, but he doesn't want to exercise. He might be able to help me a little... to set things up..." (Bridget).

\section{Fearing the future}

Participants expressed concerns and uncertainty about the future, which may have been elicited during the course of the rehabilitation. They emphasized that they feared the future and were anxious about what the future might hold for them and how they would end up. Some saw no solution to their 
situations. Others were afraid about not being able to understand things in the future and about losing the ability to engage in everyday life. They perceived having an incurable and accelerating condition as scary. Furthermore, distressing emotional responses to being in a group of participants in different stages of dementia were expressed. One woman described feeling grief when she compared herself to fellow participants, and when realizing what the next stage of the disease might be: "... have felt a sadness about being in a group... that is not constructive for me... but constructive for the purpose in this case...I never thought that I would quit or say that I won't do this, but then I already had that feeling that now I am on the threshold of something that becomes much, much worse..." (Betty).

\section{Being seen makes participation worthwhile Participation is viewed as a privilege}

It was expressed that participation in the rehabilitation was a privilege. Participants stated that they experienced the program as a fantastic and generous venture that gave silver linings to their everyday lives. Participation was described as a great benefit: "All of this arrangement is absolutely amazing... being part of it makes a difference...you get a status on how you really stand...I have also pointed out that it is incredible to be part of such a group" (Boris). The participants appreciated the invitation and felt privileged to have been selected for the rehabilitation program. They were also grateful for the ability to contribute to the research project, and felt that it was important to take part in what the rehabilitation program offered. Some experienced no rehabilitation-related change or influence in their everyday lives, but still appreciated participating as they could continue with their previous activities, such as attending lectures or continuing with chi-gong lessons. Others could not express whether any change had occurred, and stated that this was for others to decide.

\section{Responsiveness and support create security}

The participants appreciated that the staff had appropriate skills, and characteristics, and commended them for their qualities, which contributed to their well-being. The staff's support and care were responsive to their individual problems, which created security. The participants emphasized that the rehabilitation team provided great overall service and that the staff had been handpicked for the purpose: "I think what we have done has been good in many ways... and the people who have been there [the team staff] you feel that they are used to dementia, so you relax... When we sat and talked, it felt like things were normal" (Bridget). According to the participants, the staff were able to see each person's progress, and had the ability to adapt treatment to personal needs. "Yes, they are nice people [the team staff]...they have been attentive...if you ask, you get answers to everything you ask about...helpful in every way...I think that is a suitable team size anyway when doing something like this..."(Adam). The participants appreciated being greeted by staff at the entrance of the rehabilitation unit, which made them feel safe and welcomed. The assistant nurse support with practical things, including coffee breaks, was very much appreciated. Participants described the support with travel as a privilege that solved the logistical 
problem of getting to and from the day rehabilitation unit, and thus reduced potential feelings of anxiety before leaving home.

\section{Perceiving unfulfilled needs and expectations}

Some participants stated that they had needs that were not met by the rehabilitation program. They voiced, for example, wishes for more information about dementia, more help from the doctor, and more strength training. One woman expressed that she did not feel she was seen as a capable individual, and that the focus of the rehabilitation was on the informal caregivers. Participants had constructive suggestions for changes of the rehabilitation, such as group allocation based on functional level and stage of the disease. "We are not alike and have not all progressed as far in our illness, this should be the least you think of there..." (Eva). They also had different expectations about the content of the rehabilitation and what it would lead to. One expectation mentioned was taking part in lectures given to informal caregivers instead of being in the exercise session. The different focus between participants and their informal caregivers was also mentioned. One woman had wanted to find a friend during the rehabilitation, but this did not happen. Some described difficulties in adapting to the logistics of traveling between their homes and the day rehabilitation unit and that travel could cause stress and uncertainty.

\section{Feelings of togetherness in prosperity and adversity Experiencing joy and friendship}

The participants described having fun and forming friendships in the group at the day rehabilitation unit. They described the atmosphere as relaxed, supportive, and spirit-boosting. They characterized the group as stimulating, which implied a sense of being comfortable. This comfort, in turn, led them to dare to contribute to the group "In the future I think it is important for such activities, that it is a slightly smaller group that stimulates each other, because it is not every day you think positively, there are days that you are negative and you feel down... You play off each other." (Adam). The coffee break after the exercise was highlighted. Having coffee together and conversing was described as a pleasant experience. Participants felt positive about the conversations during the break, and expressed that everyone felt included and involved in the dialog. They felt able to talk like ordinary people and to discuss current topics. However, when talking about all of these positive aspects, sad feelings emerged that the rehabilitation program would end soon. They expressed that they would miss the activities, the staff and the other participants in the group: "I will miss the others in the group... / will do that... well I think it has been good...better than when you were alone" (Bridget).

\section{Perceiving obstacles to interaction}

The participants also perceived obstacles to interaction in the group setting, and described the group situation as complex given the variation in participants' abilities and personalities, which meant that it was not always easy to interpret others. The importance of contributing and communicating with each other in the group was emphasized. Some also mentioned feeling sad because they had not gotten to 
know each other well during the rehabilitation period. Others also described grief about being unable to communicate actively with everyone in the group, or to keep conversations going, as some in the group could not actively engage in the dialogue. "...We sit together around this table, but then...it can be fun if you find a topic of conversation, but it always dies away...it is not possible for these people to respond, but the staff try to keep it going further so we get some views on what we are talking about and so on, but no one comes with their own point of view connected with the topic... if so, it is something entirely different...so the conversation stops from its own lack of...fuel, so to say" (Betty).

\section{Discussion}

This is to our knowledge the first study exploring experiences of community-dwelling older people with dementia taking part in a person-centered multidimensional interdisciplinary rehabilitation program. The interpretation of the interviews was expressed as the overarching theme Empowered through participation and togetherness. Participants described that they were strengthened by facing individualized challenges during the rehabilitation. Mediated by the program, they gained insights about themselves and their condition, which motivated them to continue engaging in prioritized activities, but they also became concerned about how the future would turn out. Participation was experienced as a privilege and being seen made participation worthwhile. They described their experience of being part of the exercise group as togetherness in prosperity and adversity.

The participants in our study described being challenged in both exercise and daily activities as positive, which is in line with positive experiences of being challenged during exercise among people with dementia in nursing homes $[45,46]$. Being challenged has also been described as a mediator of motivation to continue exercising in community-dwelling people with dementia [47]. The importance of the challenges being individualized and achievable was also emphasized. Coping with challenges increased self-esteem and feelings of competence and being strengthened. Having something expected of you and being able to accomplish may result in improvement in mood and self-esteem [46]. It may be important for health and well-being to feel that one can dare and cope with activities in daily life [48]. Finding satisfaction in meaningful activities, has been emphasized in studies with people with dementia previously $[49,50]$. Meaningful activities are those that one wants to do, has to do, or needs to do during the day [51] and being able to manage without feeling dependent on others may be of importance [52]. Engagement in activities fills a void, enhances role identity, and helps people with dementia to express themselves positively [53]. These factors may in turn provide control over self-identity, a critical attribute of selfhood that may endure during the course of the disease [54].

Our findings show that people with dementia can get new insights about themselves and their condition through rehabilitation. The participants gained insight that they were able to influence their situations. They realized that they had the ability to improve their physical status and ability in daily activities, and further, that they felt satisfied with themselves and their achievements when they came home after the rehabilitation session. Engaging in regular activities also affected their mood positively and being part of the rehabilitation group led to feelings of belonging [55]. Having a sense of belonging, a social arena, 
being included in enjoyable and meaningful activities, and feeling supported $[47,56]$ have been described as important for the ability to cope with dementia [57], and may therefore positively influence health and well-being [55]. The combination of the exercise and the social activity (drinking coffee together after), strengthened the feelings of belonging and well-being, which has been voiced before [56, 58]. Meeting people in the same situation and engaging in group activities provides opportunities for a great deal of encouragement. This is in line with our clinical experience and with a previous study in people with dementia in nursing homes [45]. The finding that our participants realized that they were not alone in having dementia strengthened them in their situation [55]. Additionally, engagement in group activities can trigger reflection and adaptation [59] and relationships with other group members and leaders seem to facilitate participation [46].

Although some of them were hesitant to participate at first, our participants gradually changed their minds and became positive to participation, which is similar pattern as the increased motivation seen during exercise over time in nursing home residents [60]. People with dementia may need time to feel safe and embrace new activities and contexts [56]. The participants expressed gratitude for being able to participate in and contribute to the rehabilitation and emphasized the importance of being invested in [46]. This may have contributed to increased motivation and the willingness to make the most of the situation.

Participants in our study praised the professionals, whose responsiveness created security and support along with a welcoming atmosphere. This is in accordance with an activity center study, whose participants valued having the staff seeing them and treating them as normal people [55], and as earlier mentioned found it a motivator to engage in exercise [47]. Professional characteristics are important for the success of exercise programs $[45,46]$ and the forming of a therapeutic alliance $[61]$ is important, according to the authors' clinical experiences. Physiotherapists participating in an exercise study on people with dementia noted the importance of the ability to take a flexible approach, to engage in personalized communication, and to build successful collaboration [62]. The vast majority of professionals in this study all had experience of working with people with dementia, which probably contributed to the participants' experiences of the program.

Although mostly positive experiences about the group setting and fellow participants emerged, perceived obstacles to interaction in groups due to their diverse needs were voiced. This might be difficult to overcome in a group with a progressive neurodegenerative disease. However, as suggested by some participants, the composition of groups with more consideration of function and ability, and a group composed of those in the early stage of the disease, needs further evaluation in the future. It seems important, however, that the professionals are supportive and apply their expertise to facilitate the communication in the group settings [47]. The group setting also raised negative feelings and thoughts by, for example, comparison with fellow participants. Some participants expressed fear about their future situations, including the inability to perform activities later in life. Fear regarding the future, which may have been elucidated by rehabilitation, is important to consider when offering rehabilitation in this population. 
The results show that people with dementia may be empowered through rehabilitation. According to the World Health Organization, patient empowerment is "a process through which people gain greater control over decisions and actions affecting their health" [48] building on core values, positive experiences, possibilities and capabilities rather than problems and symptoms. Being empowered may suggest having improved self-efficacy in one's daily activities. Self-efficacy is the person's belief in their ability to succeed in a specific task. It is a critical component of motivation and affects task choices, effort, persistence and achievement [63]. The participants' self-efficacy could have increased by successful management of activities in the rehabilitation program and in daily life, by watching fellow group members successfully perform exercises, and by leaders' positive feedback and help to handle feelings [63]. Being empowered can also be interpreted according to the self-determination theory (SDT), a theory of motivation applied in research topics such as physical activity and exercise [64,65]. The rehabilitation program could have met participants' essential psychological needs for optimal functioning according to the SDT: autonomy, competence, and relatedness. The person-centered approach with individual goals and the opportunity to leave home to participate in exercise might partly have satisfied the need for autonomy. By daring and coping, successfully managing exercise and activities, the participants may have gained a feeling of competence. The need for relatedness may have been satisfied by being part of a group led by skilled leaders. Altogether, such need fulfillment could have increased participants' motivation and led to empowerment.

\section{Methodological considerations}

Some limitations of the study needs to be considered. When interviewing people with dementia, impaired memory and awareness of the disability might influence responses to questions. However, efforts were made to facilitate participants' recall as the interviews were conducted in close conjunction with the rehabilitation visits, together with the use of recall cues. The sample was selected in the sense that all had agreed to participate in the study and all participants had a MMSE score of 15 and more, which would diminish the transferability to people with more severe dementia. The depth and richness of the conversations showed that the participants were able to reflect on and describe participation in the rehabilitation program. Considering participants' experiences is of great importance when evaluating rehabilitation in general and for people with dementia in particular.

\section{Conclusion}

A person-centered multidimensional interdisciplinary rehabilitation program among community-dwelling older people with mild to moderate dementia seems feasible according to reported experiences. The participants seemed empowered through the rehabilitation and reported mostly positive experiences and which seems to affect their wellbeing and daily life. Providers of interdisciplinary rehabilitation programs for this group should consider aspects raised by the participants e.g. the positive experience of being challenged in both exercise and daily activities; the importance of being seen and feel secure; the benefits and challenges of collaboration with others in the same situation; and the generation of new perspectives on current and future situation. The findings could furthermore have a positive impact on staff attitudes 
regarding the ability of this group to participate in rehabilitation. However, more research is needed to explore and evaluate interdisciplinary rehabilitation for people with dementia in various settings, explore experiences of rehabilitation among informal primary caregivers, as well as to determine how to adjust interventions to individual courses of the dementia condition.

\section{Abbreviations}

ADL: Activities of daily living; BBS: Berg Balance Scale; BPSD: behavioral and psychological symptoms of dementia; COREQ: The Consolidated Criteria for Reporting Qualitative Research; FIM: Functional Independence Measure; GDS-15: 15 item Geriatric Depression scale; HIFE: the High-Intensity Functional Exercise Program; MD: medical doctor; MIDRED: the Multidimensional Interdisciplinary Rehabilitation in Dementia study; MMSE: Mini-Mental State Examination; OT: Occupational therapist; PT: Physiotherapist; SDT: the self-determination Theory.

\section{Declarations}

\section{Ethical approval and consent to participate}

The Regional Ethics Review Board of Umeå, Sweden, approved the study (Ref. no.: 2015-293-31M, 2015450-32M), including the informed consent procedure. The participants were given written and oral information about the study, and informed that participation was voluntary and could be discontinued at any time without the need to provide a reason. Included participants gave verbal consent to participate, which was confirmed verbally by their next of kin and documented.

\section{Consent for publication}

Not applicable.

\section{Availability of data and materials}

The datasets generated and analysed during this study are not publicly available to protect the participant's confidentially. However, they are available from corresponding author upon reasonable request.

\section{Competing interests}

$\mathrm{HL}$ and $\mathrm{NL}$ developed and have received royalties for the weighted belt used in the exercise program. All other authors declare no conflict of interest.

\section{Funding}

This research was funded by Forte: Swedish Research Council for Health, Working and Welfare, the Promobilia Foundation, the Swedish Dementia Association, the Foundation of Family Janne Elgqvist, the 
County Council of Västerbotten, the Umeå University Foundation for Medical Research, the Swedish Alzheimer Foundation, the Foundation of Gamla Tjänarinnor.

\section{Authors' contribution}

All authors meet the International Committee of Medical Journal Editors criteria for authorship. Authors AS, JL, MC, UE, HL, IN, and NL contributed to conceptualisation, design of the study and interpretation of data. AS, IN, and NL performed the interview data collection. AS, and JL with support from NL, and IN analysed the data. AS with support from JL drafted the manuscript. All authors revised the manuscript for important intellectual content and approved the final version.

\section{Acknowledgements}

We would like to express our sincere gratitude to the participant and the County Council of Västerbotten. We would also like to thank Sanna Wiljeskén, PT, Josefın Fhärm, FT, Jerry Öhlin, PT, and Annika Toots, PT, for their effort in the data collection; Låtta Hasselgren, PT, Caroline Ollman, OT, Anna Hollander, MD, Eric Stjernberger, MD, Karin Nordvall, nurse, Maine Carlsson, dietician, Anita Ericson, neuropsychologist, Gun Zakrisson, assistant nurse, Birgitta Rönnmark, social worker, Maria Gustafsson, pharmacist, and Elisabeth Johansson, dental hygienist, for their effort in the implementation of the intervention.

\section{References}

1. World Health Organisation. Dementia: a public health priority. 2012. http://www.who.int/mental_health/publications/dementia_report_2012/en/.

2. Allali G, Annweiler C, Blumen HM, Callisaya ML, De Cock AM, Kressig RW, et al. Gait phenotype from mild cognitive impairment to moderate dementia: results from the GOOD initiative. Eur J Neurol. 2016;23(3):527 - 41.

3. Sherrington C, Michaleff ZA, Fairhall N, Paul SS, Tiedemann A, Whitney J, et al. Exercise to prevent falls in older adults: an updated systematic review and meta-analysis. Br J Sports Med. 2016.

4. Lundstrom M, Olofsson B, Stenvall M, Karlsson S, Nyberg L, Englund U, et al. Postoperative delirium in old patients with femoral neck fracture: a randomized intervention study. Aging Clin Exp Res. 2007;19(3):178 - 86.

5. Williams AK. Motivation and dementia. Topics in Geriatric Rehabilitation. 2005;21(2):123-6.

6. David R, Mulin E, Friedman L, Le Duff F, Cygankiewicz E, Deschaux O, et al. Decreased daytime motor activity associated with apathy in Alzheimer disease: an actigraphic study. Am J Geriatr Psychiatry. 2012;20(9):806 - 14.

7. Kuiper JS, Zuidersma M, Zuidema SU, Burgerhof JG, Stolk RP, Oude Voshaar RC, et al. Social relationships and cognitive decline: a systematic review and meta-analysis of longitudinal cohort studies. Int J Epidemiol. 2016;45(4):1169 - 206. 
8. Pettersson AF, Engardt M, Wahlund LO. Activity level and balance in subjects with mild Alzheimer's disease. Dement Geriatr Cogn Disord. 2002;13(4):213-6.

9. Holt-Lunstad J, Smith TB, Baker M, Harris T, Stephenson D. Loneliness and social isolation as risk factors for mortality: a meta-analytic review. Perspect Psychol Sci. 2015;10(2):227 - 37.

10. Lee IM, Shiroma EJ, Lobelo F, Puska P, Blair SN, Katzmarzyk PT, et al. Effect of physical inactivity on major non-communicable diseases worldwide: an analysis of burden of disease and life expectancy. Lancet. 2012;380(9838):219 - 29.

11. Hajjar ER, Hanlon JT, Artz MB, Lindblad Cl, Pieper CF, Sloane RJ, et al. Adverse drug reaction risk factors in older outpatients. Am J Geriatr Pharmacother. 2003;1(2):82 - 9.

12. Bergdahl E, Allard P, Gustafson Y. Depression among the very old with dementia. Int Psychogeriatr. 2011;23(5):756 - 63.

13. Lövheim H, Sandman PO, Kallin K, Karlsson S, Gustafson Y. Relationship between antipsychotic drug use and behavioral and psychological symptoms of dementia in old people with cognitive impairment living in geriatric care. Int Psychogeriatr. 2006;18(4):713 - 26.

14. Schulz R, Martire LM. Family caregiving of persons with dementia: prevalence, health effects, and support strategies. Am J Geriatr Psychiatry. 2004;12(3):240-9.

15. The National Board of Health and Welfare. Care and treatment of people with dementia disease. 2017. The national guidelines for care and treatment of people with dementia diseases.https://www.socialstyrelsen.se/Lists/Artikelkatalog/Attachments/20739/2017-122.pdf2017. (Publication in Swedish).

16. Gallagher D, Coen R, Kilroy D, Belinski K, Bruce I, Coakley D, et al. Anxiety and behavioural disturbance as markers of prodromal Alzheimer's disease in patients with mild cognitive impairment. Int $\mathrm{J}$ Geriatr Psychiatry. 2011;26(2):166 - 72.

17. World Health Organisation. Rehabilitation 2030 a call for action. 2017. https://www.who.int/disabilities/care/rehab-2030/en/2017.

18. World Health Organization. Global action plan on public health response to dementia 2017-2025. https://apps.who.int/iris/bitstream/handle/10665/259615/9789241513487eng.pdf;jsessionid=4485694461654C53C9870FF7BC8C4C51 ? sequence $=12017$.

19. Khan F, Turner-Stokes L, Ng L, Kilpatrick T. Multidisciplinary rehabilitation for adults with multiple sclerosis. Cochrane Database Syst Rev. 2007(2):CD006036.

20. Langhorne P, Bernhardt J, Kwakkel G. Stroke rehabilitation. Lancet. 2011;377(9778):1693 - 702.

21. Low LF, Swaffer K, McGrath M, Brodaty H. Do people with early stage dementia experience Prescribed Disengagement(R)? A systematic review of qualitative studies. Int Psychogeriatr. 2018;30(6):807 - 31.

22. Cations M, May N, Crotty M, Low LF, Clemson L, Whitehead C, et al. Health Professional Perspectives on Rehabilitation for People With Dementia. Gerontologist. 2019. 
23. Cations M, Laver KE, Crotty M, Cameron ID. Rehabilitation in dementia care. Age Ageing. 2018;47(2):171-4.

24. Isbel ST, Jamieson MI. Views from health professionals on accessing rehabilitation for people with dementia following a hip fracture. Dementia (London). 2017;16(8):1020-31.

25. Seitz DP, Gill SS, Gruneir A, Austin PC, Anderson GM, Bell CM, et al. Effects of dementia on postoperative outcomes of older adults with hip fractures: a population-based study. J Am Med Dir Assoc. 2014;15(5):334 - 41.

26. Zupanic E, Kareholt I, Norrving B, Secnik J, von Euler M, Winblad B, et al. Acute Stroke Care in Dementia: A Cohort Study from the Swedish Dementia and Stroke Registries. J Alzheimers Dis. 2018;66(1):185 - 94.

27. Stenvall $M$, Berggren $M$, Lundstrom $M$, Gustafson $Y$, Olofsson $B$. A multidisciplinary intervention program improved the outcome after hip fracture for people with dementia-subgroup analyses of a randomized controlled trial. Arch Gerontol Geriatr. 2012;54(3):e284-9.

28. Stenvall M, Olofsson B, Lundström M, Englund U, Borssen B, Svensson O, et al. A multidisciplinary, multifactorial intervention program reduces postoperative falls and injuries after femoral neck fracture. Osteoporos Int. 2007;18(2):167 - 75.

29. Allen J, Koziak A, Buddingh S, Liang J, Buckingham J, Beaupre LA. Rehabilitation in patients with dementia following hip fracture: a systematic review. Physiother Can. 2012;64(2):190-201.

30. Momsen AM, Rasmussen JO, Nielsen CV, Iversen MD, Lund H. Multidisciplinary team care in rehabilitation: an overview of reviews. J Rehabil Med. 2012;44(11):901 - 12.

31. Chew J, Chong MS, Fong YL, Tay L. Outcomes of a multimodal cognitive and physical rehabilitation program for persons with mild dementia and their caregivers: a goal-oriented approach. Clin Interv Aging. 2015;10:1687-94.

32. Dutzi I, Schwenk M, Kirchner M, Bauer JM, Hauer K. Cognitive Change in Rehabilitation Patients with Dementia: Prevalence and Association with Rehabilitation Success. J Alzheimers Dis. 2017;60(3):1171-82.

33. Spijker A, Vernooij-Dassen M, Vasse E, Adang E, Wollersheim H, Grol R, et al. Effectiveness of nonpharmacological interventions in delaying the institutionalization of patients with dementia: a meta-analysis. J Am Geriatr Soc. 2008;56(6):1116-28.

34. Folstein MF, Folstein SE, McHugh PR. "Mini-mental state". A practical method for grading the cognitive state of patients for the clinician. J Psychiatr Res. 1975;12(3):189 - 98.

35. American Psychiatric Assocation. Diagnostic and Statistical Manual of Mental Distorders, 4th ed.: Washington DC: American Psychiatric Association; 2000.

36. Berg KO, Wood-Dauphinee SL, Williams JI, Maki B. Measuring balance in the elderly: validation of an instrument. Can J Public Health. 1992;83 Suppl 2:S7-11.

37. McDowel I. Measuring Health. A Guide to Rating Scales and Questionnaires.: Oxford University Press; 2006. 
38. Graneheim UH, Lundman B. Qualitative content analysis in nursing research: concepts, procedures and measures to achieve trustworthiness. Nurse Educ Today. 2004;24(2):105 - 12.

39. Graneheim UH, Lindgren BM, Lundman B. Methodological challenges in qualitative content analysis: A discussion paper. Nurse Educ Today. 2017;56:29-34.

40. Tong A, Sainsbury P, Craig J. Consolidated criteria for reporting qualitative research (COREQ): a 32item checklist for interviews and focus groups. Int J Qual Health Care. 2007;19(6):349 - 57.

41. Littbrand H, Lindelöf N, Rosendahl E. The High Intensity Functional Exercise (HIFE) Program. https://www.hifeprogram.se/en: Department of Community Medicin and Rehabilitation, Umeå University, Sweden. 2018.

42. Littbrand H, Rosendahl E, Lindelöf N, Lundin-Olsson L, Gustafson $Y$, Nyberg L. A high-intensity functional weight-bearing exercise program for older people dependent in activities of daily living and living in residential care facilities: evaluation of the applicability with focus on cognitive function. Phys Ther. 2006;86(4):489 - 98.

43. American College of Sports M, Chodzko-Zajko WJ, Proctor DN, Fiatarone Singh MA, Minson CT, Nigg $\mathrm{CR}$, et al. American College of Sports Medicine position stand. Exercise and physical activity for older adults. Med Sci Sports Exerc. 2009;41(7):1510-30.

44. World Health Organisation. Global recommendations on physical activity for health. Geneva, Switzerland, 2010.

45. Lindelöf N, Lundin-Olsson L, Skelton DA, Lundman B, Rosendahl E. Experiences of older people with dementia participating in a high-intensity functional exercise program in nursing homes: "While it's tough, it's useful". PLoS One. 2017;12(11):e0188225.

46. Olsen CF, Telenius EW, Engedal K, Bergland A. Increased self-efficacy: the experience of high-intensity exercise of nursing home residents with dementia - a qualitative study. BMC Health Serv Res. 2015;15:379.

47. Di Lorito C, Bosco A, Pollock K, das Nair RHH, Logan R P, et al. External Validation of the 'PHYT in Dementia', a Theoretical Model Promoting Physical Activity in People with Dementia. Int J Environ Res Public Health. 2020;17(5).

48. World Health Organisation. Global health and ageing 2011.

49. Berg Al, Wallin A, Nordlund A, Johansson B. Living with stable MCl: experiences among 17 individuals evaluated at a memory clinic. Aging Ment Health. 2013;17(3):293-9.

50. Bielsten T, Lasrado R, Keady J, Kullberg A, Hellstrom I. Living Life and Doing Things Together: Collaborative Research With Couples Where One Partner Has a Diagnosis of Dementia. Qual Health Res. 2018;28(11):1719-34.

51. Gillen G. Occupational therapy interventions for Individuals in Willard and Spackman's Occupational Therapy 13 th ed. Kluwer. W, editor2019.

52. Randstrom KB, Asplund K, Svedlund M, Paulson M. Activity and participation in home rehabilitation: older people's and family members' perspectives. J Rehabil Med. 2013;45(2):211-6. 
53. Kolanowski A, Buettner L, Costa P. Capturing interests: Therapeutic recreation activities for persons with dementia. Ther Recreation J. 2001;35:229 - 35.

54. Cohen-Mansfield J, Parpura-Gill A, Golander H. Utilization of self-identity roles for designing interventions for persons with dementia. J Gerontol B Psychol Sci Soc Sci. 2006;61(4):P202-12.

55. Söderhamn U, Aasgaard L, Landmark B. Attending an activity center: positive experiences of a group of home-dwelling persons with early-stage dementia. Clin Interv Aging. 2014;9:1923-31.

56. Taraldsen K, Boulton E, Helbostad JL, Saltvedt I, Granbo R. Client, caregiver, volunteer, and therapist views on a voluntary supported group exercise programme for older adults with dementia. BMC Geriatr. 2020;20(1):235.

57. Steeman E, de Casterle BD, Godderis J, Grypdonck M. Living with early-stage dementia: a review of qualitative studies. J Adv Nurs. 2006;54(6):722 - 38.

58. Nilsson I, Lundgren AS. Making meaning around experiences in interventions: identifying meaningfulness in group-based occupational therapy intervention targeting older people. Ageing and Society. 2017;38(9):1887 - 911.

59. Nilsson I, Nygaard L. Geriatric Rehabilitation: Elderly Clients' Experiences of a Pre-discharge Occupational Therapy Group Programme. Scand J Occup Ther. 2003;10(3):107 - 17.

60. Sondell A, Rosendahl E, Sommar JN, Littbrand H, Lundin-Olsson L, Lindelöf N. Motivation to participate in high-intensity functional exercise compared with a social activity in older people with dementia in nursing homes. PLoS One. 2018;13(11):e0206899.

61. Vestol I, Debesay J, Pajalic Z, Bergland A. The importance of a good therapeutic alliance in promoting exercise motivation in a group of older Norwegians in the subacute phase of hip fracture; a qualitative study. BMC Geriatr. 2020;20(1):118.

62. Fjellman-Wiklund A, Nordin E, Skelton DA, Lundin-Olsson L. Reach the Person behind the Dementia Physical Therapists' Reflections and Strategies when Composing Physical Training. PLoS One. 2016;11(12):e0166686.

63. Schunk DH, Usher EL. Social Cognitive Theory and Motivation. In: Ryan RM, editor. The Oxford Handbook of Human Motivation: Oxford Library of Psychology; 2012 Press. p. 13-27.

64. Deci EL, Ryan RM. Self-Determination Theory: A Macrotheory of Human Motivation, Development, and Health. Canadian Psychology-Psychologie Canadienne. 2008;49(3):182-5.

65. Ryan RM, Deci EL. Self-determination theory and the facilitation of intrinsic motivation, social development, and well-being. Am Psychol. 2000;55(1):68-78. 